\title{
Visceral Fat is Better Related To Liver Function and Lipid Metabolism Than Body Mass Index and Waist Circumference: A Cross-Sectional Study
}

\section{Haiteng Zhou}

Southeast University

Guiju Sun ( $\square$ gjsun@seu.edu.cn )

Southeast University https://orcid.org/0000-0001-5969-2185

\section{Youwen Pan \\ Laian People's hospital}

\section{Bin Wang}

Laian People's Hospital

Wei Wang

$$
\text { Laian People's Hospital }
$$

Hui Xia

Southeast University

\section{Research}

Keywords: obesity, lipid metabolism, visceral fat, body mass index, liver function

Posted Date: August 31st, 2021

DOl: https://doi.org/10.21203/rs.3.rs-823614/v1

License: (1) This work is licensed under a Creative Commons Attribution 4.0 International License. Read Full License 


\section{Abstract}

Objective: The role of visceral fat area (VFA) in the metabolism of lipid and liver function was not known. To compare and evaluate the correlation of VFA, waist circumference (WC) and Body mass index (BMI) measured by Bioelectrical impedance (BIA) in terms of lipid metabolism and liver function. Receiver operating characteristic curve (ROC curve), optimum cut-off points and odds ratio (OR) for liver function and lipid metabolism variables were recommended.

Methods: A cross-sectional study was conducted on the subjects with the diagnose of obesity, including normal, overweight and obesity groups Direct Segmental Multi-Frequency Biolectrical Impedance technology was used to analysze body composition and biochemical indicators were tested. Participants were divided into normal and unnormal groups by lipid and liver indicators, cut off value of VFA and related variables was calculated by ROC analysis and multiple logistic regression analysis were conducted.

Results: Ninety-five participants were enrolled in this study, fifty-seven (60\%) were male, and the average age was thirty-four years old. Compared with normal group, high density lipoprotein (HDL) and low density lipoprotien (LDL) disorder groups have a higher VFA (normal HDL group $87.3 \mathrm{~cm}^{2}<$ unnormal HDL group $115.8 \mathrm{~cm}^{2}$; normal LDL group $90.5 \mathrm{~cm}^{2}<$ unnormal LDL group $\left.109.0 \mathrm{~cm}^{2}, \mathrm{p}<0.05\right)$. VFA was higher in the lactate dehydrogenase (LDH) disorder group than in the normal, and the difference was significant $\left(144.6 \mathrm{~cm}^{2}>96.2 \mathrm{~cm}^{2}, p=0.016\right)$. BMI, WC and VFA values was manifested positively correlated to glutamic oxaloacetic transaminase (AST) and alanine aminotransferase (ALT), respectively. Area under the curve (AUC) of VFA was over than 0.7 revealed great ability of related to lipid HDL metabolism $(p=0.004)$. VFA (AUC $=0.701,95 \% \mathrm{Cl} 0.577-0.826, \mathrm{p}=0.004)$ provides a better diagnostic accuracy to distinguish between HDL disorder and normal groups. The optimal cut-off value for VFA was $80.2 \mathrm{~cm}^{2}$ with $81.3 \%$ sensitivity and $56.8 \%$ specificity. For LDH disorder, a cut-off value of VFA $125.3 \mathrm{~cm}^{2}$ shows a sensitivity of $83.3 \%$ and specificity of $78.9 \%$ ( $A U C=0.792,95 \% \mathrm{Cl} 0.595-0.989, \mathrm{p}=0.019$ ). The risk of lipid metabolism disorder and liver dysfunction were explored, and Multivariate analysis showed that VFA $>80.2 \mathrm{~cm}^{2}(\mathrm{OR}=2.81$, $p=0.034)$ was a significantly risk factor related to $H D L$ disorder and $V F A>125.3 \mathrm{~cm}^{2}(O R=18.75, P=0.01)$ was the risk factor for LDH disorder. While, WC and BMI wasn't in the regression equation.

Conclusion: VFA was more reliable and related to the lipid metabolism and liver function. VFA could be used as an independent indicator for the evaluation of the risk lipid metabolism disorder and liver dysfunction.

\section{Introduction}

Obesity is one of common public health burden globally. According to the World Health Organization data 2021, adults aged 18 years and over with $13 \%$ were obesity, and obesity has nearly tripled since 1975 worldwide ${ }^{[1]}$. The latest report on nutrition and chronic diseases shows that the incidence of overweight and obesity in Chinese adults is $34.3 \%$ and $16.4 \%$, respectively. Obesity has become one of the most 
prominent problems in China (2020). Chronic noncommunicable diseases were associated with obesity such as cardiovascular diseases, diabetes, metabolic syndrome and hypertension ${ }^{[2]}$. In oldest-old adults, visceral fat area was the best discriminator for obesity associated with mobility disability ${ }^{\left[{ }^{[}\right]}$. Bertin revealed that obesity and Crohn's disease share common features with the development of mesenteric fat that may be involved in gut inflammation ${ }^{[4]}$. Jung revealed that visceral fat mass measured using DXA is an indicator of diabetes or prediabetes ${ }^{[5]}$. Visceral abdominal and perivascular fat depots assessed as ultrasound indexes are associated with complications of hypertension ${ }^{[6]}$.

The measurements of obesity were mostly conducted by body mass index (BMI). According to world health organization (WHO) criteria, $\mathrm{BMI} \geq 30 \mathrm{~kg} / \mathrm{m}^{2}$ or waist circumference (male $\geq 102 \mathrm{~cm}$, female $\geq$ $88 \mathrm{~cm}$ ) would be diagnosed obesity. In addition, the critical value of body fat content or other obesity indexes are also useful indicators for measuring obesity ${ }^{[7]}$. The measurements of fats were conducted by Skinfold thickness, magnetic resonance imaging (MRI), dual energy X-ray (DXA), computed tomography (CT) and bioelectrical impedance (BIA) commonly. Bioelectrical impedance technology as a non-invasive detection technology, which has been widely used in the diagnose of diseases, such as obesity, sarcopenia obesity, diabetes, cardiovascular disease risk prediction, nutritional risk of surgical patients and protein calorie malnutrition of renal dialysis patients ${ }^{[8,9]}$. Based on the electrical conductivity of human tissue, the bioelectrical impedance of human body can be measured at different frequencies through weak current; the content of human body components can be obtained by further calculating the bioelectrical impedance mode and phase angle ${ }^{[10]}$. Research has been showed, percentage body fat classified more obesity than BMI and FMI from the $50-59$ groups $^{[11]}$.

Prevent research has been revealed with the increasing of fat, the response of target tissue to insulin would be reduced and then insulin resistance appears, which in turn promotes the occurrence of metabolic syndrome and obesity ${ }^{[12,13]}$. Bouchi's study revealed with the decrease of abdominal fat could improve hyperglycemia and chronic inflammation in type 2 diabetes (T2D) ${ }^{[14]}$. In Kim's study, high fat was significantly associated with the prevalence of metabolic syndrome (incidence rate ratios, IRR: 2.30 ) ${ }^{[15]}$. In Badawi's BMI and latent tuberculosis study, there was a particularly apparent in the increased levels of triglycerides, cholesterol, fasting glucose, and glycosylated hemoglobin (HbA1C) levels in the Latent Tuberculosis Infection (LTBI) group and overweight subgroups ${ }^{[16]}$. Marit et al found the visceral fat was better related to the glucose metabolism than $\mathrm{BMI}^{[17]}$. Previous study on the influence of visceral Obesity on vascular structure and function in obese subjects has been identified visceral fat deposit would be increased risk of atherosclerosis and liver disease ${ }^{[18]}$. In the study of association between visceral abdominal fat accumulation and severity of liver fibrosis, Soldevila et al found $65 \%$ and $54 \%$ of patients had AST and ALT concentrations above normal values and VFA was a credible variable for the prediction of cirrhosis ${ }^{[19]}$. Darvishi indicated raised AST level was the independent risk factors for the Vit-D insufficiency in beta-thalassemia patients ${ }^{[20]}$. One study illustrated that leptin enhances hypothalamic lactate dehydrogenase A (LDHA) dependent glucose sensing to lower glucose production in high-fat-fed rodents in vivo[21]. 
Studies have been revealed that BMI, WC and visceral fat (VF) were related to the glucose metabolism, lipid metabolism and liver function. While, the comparison of BMI, WC and VFA by BIA on the lipid metabolism and liver functions were not compared by previous study, and variables ROC curve and optimum cut-off points were not recommended. Our research was to compare and evaluate the correlation of VFA, WC and BMI measured by BIA to lipid metabolism and liver function. Besides, ROC curve, optimum cut-off points and OR value for liver function and lipid metabolism disorder variables were recommended.

\section{Methods And Materials}

A cross-sectional study was conducted on the patients with the diagnose of obesity. Data were collected between Jan 2019 and June 2020 in Laian People's Hospital, Anhui Province, China. This study was secondary research based on diagnose and management of obesity and data were recruited by regular physical examination. Criteria and categories for obesity were reference to the diagnosis criteria of World Health Organization (WHO). 95 participants were enrolled in this study, including normal, overweight and obesity subjects. Besides, all the participants were signed Informed consent.

\section{Data collection}

Direct Segmental Multi-Frequency Biolectrical Impedance technology was used to analysze body composition (InBody ${ }^{\circledR}$ model 770). All the recruited participants would be finished body composition analysis with four couple of electrode holders placed on the ankles and forefingers of the hands, and at least 8 hours or overnight fasting with light clothes on the body. Weight, VFA, WC, BMI were obtained by this instrument. Height was measured by height meter (InBody® model BSM 170), and BMI were calculated.

\section{Biochemical data}

Biochemical variables related to liver profile and lipid metabolism serum triglyceride (TG), total cholesterol (TC), HDL, LDL, total bilirubin (TB), AST, Glutamyltranspeptidase (GGT), ALT, LDH and alkaline phosphatase (ALP) were determined by Absorption spectrometry automatic biochemical analyzer (LX20; Beckman, Brea, CA,USA), and we conduct a further analyze based on these medical testing data(serum biomarkers must be tested during the process the diagnose of obesity and regular medical physical examination). Serum lipid metabolism disorder diagnosis: total cholesterol $>200 \mathrm{mg} / \mathrm{dL}$, HDL-cholesterol $<40 \mathrm{mg} / \mathrm{dL}$ in men and $<50 \mathrm{mg} / \mathrm{dL}$ in women; LDL-cholesterol $>100 \mathrm{mg} / \mathrm{dL}$; and serum triglycerides $>150$ $\mathrm{mg} / \mathrm{dL}^{[22]}$.

\section{Statistical Analyses}

Normal distribution data were presented as Mean $\pm S D$, and numeric variables were presented by median and interquartile distance. Student's t test or Fisher's exact test was used to analyze the difference between groups; univariable regression was used between body composition, biochemical variables with 
BMI, WC and VFA. ROC and AUC, cut-off values were calculated. With the ROC optimum cut-off values, Chi square analysis was conducted, OR and $95 \%$ confidence interval $(95 \% \mathrm{Cl})$ ware calculated. $\mathrm{p}$ value < 0.05 was considered to be statistically significant.

\section{Results}

Ninety-five participants were enrolled in this study, fifty-seven (60\%) were male, and the average age was thirty-four years old. Participants demographical and body composition parameters are shown in Table 1.

Table 1

Participants demographic characteristics

\begin{tabular}{|ll|}
\hline Variables & Mean \pm SD/Median (percentage/IQR) \\
\hline \multicolumn{2}{|l|}{ Body composition indicators } \\
\hline Men & $57(60 \%)$ \\
\hline Age & $34.3 \pm 15.12$ \\
\hline Height(cm) & $168.1 \pm 7.76$ \\
\hline Weight(kg) & $74.6 \pm 17.29$ \\
\hline Body mass index $(\mathrm{kg} / \mathrm{m} 2)$ & $26.3 \pm 5.13$ \\
\hline Waist circumference $(\mathrm{cm})$ & $87.9 \pm 14.64$ \\
\hline Visceral fat area(cm2) & $96.7 \pm 48.98$ \\
\hline Liver function indicators & \\
\hline TB & $12.4(8.9)$ \\
\hline LDH & $191.0(79.5)$ \\
\hline ALT & $24.0(30.0)$ \\
\hline AST & $23.5(17.3)$ \\
\hline ALP & $78.0(29.0)$ \\
\hline GGT & $25.0(34.0)$ \\
\hline Lipid metabolism indicators & \\
\hline TG & $4.8 \pm 1.23$ \\
\hline TC & $3.0 \pm 0.91$ \\
\hline HDL & \\
\hline LDL & \\
\hline
\end{tabular}


The difference of obesity indicators BMI, WC and VFA were analyzed between lipid metabolism variables TG, TC, HDL and LDL normal and unnormal groups. According to medical diagnosis results of TG and $\mathrm{TC}$, there is no significant difference in the comparison of BMI, WC and VFA between normal and unnormal groups. While in HDL and LDL normal groups, VFA were lower than unnormal groups and significant statistics were obtained $(P<0.05)$. $\mathrm{HDL}$ and $\mathrm{LDL}$ disorder group with a higher VFA, while there are no significant differences in BMI, WC between normal and unnormal groups for serum HDL and LDL levels. This may indicate VFA has a better predicational ability in the diagnosis of lipid metabolism than $\mathrm{BMI}$ and WC (Table 2).

Table 2

Comparison of obesity variables between lipid metabolism indicators

\begin{tabular}{|llll|}
\hline Variables & Normal & Unnormal & p value \\
\hline TG & & & \\
\hline BMI & $27.2 \pm 4.59$ & $27.4 \pm 4.80$ & 0.872 \\
\hline WC & $90.1 \pm 14.54$ & $90.2 \pm 14.24$ & 0.973 \\
\hline VFA & $103.5 \pm 53.59$ & $102.5 \pm 41.34$ & 0.937 \\
\hline TC & & & 0.648 \\
\hline BMI & $27.2 \pm 4.34$ & $26.7 \pm 4.57$ & 0.953 \\
\hline WC & $88.8 \pm 14.88$ & $89.0 \pm 12.78$ & 0.212 \\
\hline VFA & $103.6 \pm 50.82$ & $89.9 \pm 39.51$ & 0.298 \\
\hline HDL & & & 0.104 \\
\hline BMI & $26.9 \pm 4.92$ & $28.0 \pm 3.54$ & $0.010^{*}$ \\
\hline WC & $87.6 \pm 15.35$ & $93.0 \pm 11.17$ & 0.223 \\
\hline VFA & $87.3 \pm 47.99 *$ & $115.8 \pm 40.49 *$ & 0.138 \\
\hline LDL & & & $0.049 *$ \\
\hline BMI & $26.5 \pm 4.37$ & $27.8 \pm 4.32$ & \\
\hline WC & $87.0 \pm 14.15$ & $91.8 \pm 12.23$ & \\
\hline VFA & $90.5 \pm 50.05 *$ & $109.0 \pm 40.34 *$ & \\
\hline Note: Mean \pm SD. & & & \\
\hline * Compared with lipid metabolism disorder group, $p<0.05$ means statistical significance. & \\
\hline
\end{tabular}


The difference of BMI, WC and VFA were analyzed between liver function variables TB, AST, GGT, ALT, LDH and ALP comparison groups, respectively. According to biochemical testing results, VFA was higher in the LDH disorder group than in the normal, and the difference was significant $\left(144.6 \mathrm{~cm}^{2}>96.2 \mathrm{~cm}^{2}, \mathrm{p}=\right.$ 0.016). BMI, WC and VFA were manifested positively correlated to ALT and AST. (Table 3). 
Table 3

Comparison of obesity variables between liver function indicators

\begin{tabular}{|c|c|c|c|}
\hline Variables & Normal & Unnormal & $p$ value \\
\hline \multicolumn{4}{|l|}{ TB } \\
\hline BMI & $26.4 \pm 5.23$ & $25.6 \pm 4.91$ & 0.485 \\
\hline WC & $88.6 \pm 14.49$ & $85.1 \pm 15.35$ & 0.329 \\
\hline VFA & $100.6 \pm 50.40$ & $81.9 \pm 41.93$ & 0.118 \\
\hline \multicolumn{4}{|l|}{ LDH } \\
\hline BMI & $26.7 \pm 4.94$ & $25.5 \pm 6.65$ & 0.353 \\
\hline WC & $89.2 \pm 14.27$ & $85.5 \pm 17.17$ & 0.361 \\
\hline VFA & $96.2 \pm 45.05^{*}$ & $144.6 \pm 50.13^{*}$ & 0.016 \\
\hline \multicolumn{4}{|l|}{ ALT } \\
\hline BMI & $25.7 \pm 4.27^{*}$ & $29.8 \pm 6.08^{\star}$ & 0.037 \\
\hline WC & $85.6 \pm 12.60^{*}$ & $98.5 \pm 13.43^{*}$ & 0.006 \\
\hline VFA & $88.4 \pm 42.45^{\star}$ & $38.8 \pm 43.03^{*}$ & 0.003 \\
\hline \multicolumn{4}{|l|}{ AST } \\
\hline BMI & $26.7 \pm 3.97^{\star}$ & $32.1 \pm 6.05^{\star}$ & 0.003 \\
\hline WC & $88.2 \pm 13.04^{\star}$ & $104.1 \pm 13.70^{*}$ & 0.006 \\
\hline VFA & $95.5 \pm 43.67^{*}$ & $142.1 \pm 53.75^{*}$ & 0.017 \\
\hline \multicolumn{4}{|l|}{ ALP } \\
\hline BMI & $26.3 \pm 5.13$ & - & - \\
\hline WC & $87.9 \pm 14.64$ & - & - \\
\hline VFA & $96.7 \pm 48.98$ & - & - \\
\hline \multicolumn{4}{|l|}{ GGT } \\
\hline BMI & $25.9 \pm 5.01$ & $27.5 \pm 5.40$ & 0.178 \\
\hline WC & $86.4 \pm 14.52$ & $92.1 \pm 14.46$ & 0.100 \\
\hline VFA & $94.5 \pm 50.65$ & $103.2 \pm 44.03$ & 0.456 \\
\hline Note: Mea & & & \\
\hline
\end{tabular}


The variables BMI, WC and VFA ROC curve were drawn. AUC, the premium cutoff points, sensitivity, and specificity were calculated. VFA presented a distinguished difference in HDL and LDL disorder groups (Fig. 1). The AUC and premium cutoff points for VFA, BMI and WC were showed in Table 4. AUC of VFA was over than 0.7 revealed great ability of related to lipid HDL metabolism $(p=0.004)$. Based on the ROC cutoff points, chi-square test was conducted between HDL and LDL groups, OR (odds ratio) and 95\% $\mathrm{Cl}$ (95\% confidence interval) were calculated. Figures 1 and 2 showed the ROC curves with the value of diagnostic accuracy of lipid metabolism and liver function in the identification of disorder. The curve reveals that VFA (AUC $=0.701,95 \% \mathrm{Cl} 0.577-0.826, p=0.004$ ) provides a better diagnostic accuracy to distinguish between HDL disorder and normal groups. The optimal cut-off value for VFA was $80.2 \mathrm{~cm}^{2}$ with $81.3 \%$ sensitivity and $56.8 \%$ specificity. For LDH disorder, a cut-off value of VFA $125.3 \mathrm{~cm}^{2}$ shows a sensitivity of $83.3 \%$ and specificity of $78.9 \%$ (AUC $=0.792,95 \% \mathrm{Cl} 0.595-0.989, p=0.019)$. In AST and ALT indicators groups, BMI, WC and VFA were also showed good prompting ability of disorder with significant values (Table 4). 
Table 4

AUC of VFA, BMI, WC and premium cutoff points from indicator's ROC

\begin{tabular}{|c|c|c|c|c|c|}
\hline Variables & Area & $P$ value & $95 \% \mathrm{Cl}$ & Sensitivity & Specificity \\
\hline \multicolumn{6}{|l|}{ HDL } \\
\hline $\mathrm{BMI}<25.7 \mathrm{~kg} / \mathrm{m}^{2}$ & 0.610 & 0.118 & $\begin{array}{l}0.495- \\
0.759\end{array}$ & 81.3 & 45.9 \\
\hline$W C<79.7 \mathrm{~cm}$ & 0.627 & 0.070 & $\begin{array}{l}0.475- \\
0.744\end{array}$ & 93.8 & 35.1 \\
\hline VFA $<80.2 \mathrm{~cm}^{2}$ & 0.701 & 0.004 & $\begin{array}{l}0.577- \\
0.826\end{array}$ & 81.3 & 56.8 \\
\hline \multicolumn{6}{|l|}{ LDL } \\
\hline $\mathrm{BMI}<25.7 \mathrm{~kg} / \mathrm{m}^{2}$ & 0.602 & 0.135 & $\begin{array}{l}0.471- \\
0.732\end{array}$ & 72.7 & 46.3 \\
\hline$W C<80.3 \mathrm{~cm}$ & 0.593 & 0.171 & $\begin{array}{l}0.464- \\
0.723\end{array}$ & 84.8 & 34.1 \\
\hline VFA $<78.6 \mathrm{~cm}^{2}$ & 0.629 & 0.058 & $0.500-0.758$ & 78.8 & 53.7 \\
\hline \multicolumn{6}{|l|}{ LDH } \\
\hline $\mathrm{BMI}<34.3 \mathrm{~kg} / \mathrm{m}^{2}$ & 0.678 & 0.153 & $\begin{array}{l}0.423- \\
0.934\end{array}$ & 50.0 & 93.0 \\
\hline$W C<93.2 \mathrm{~cm}$ & 0.709 & 0.094 & $\begin{array}{l}0.496- \\
0.922\end{array}$ & 83.3 & 66.7 \\
\hline VFA $<125.3 \mathrm{~cm}^{2}$ & 0.792 & 0.019 & $\begin{array}{l}0.595- \\
0.989\end{array}$ & 83.3 & 78.9 \\
\hline \multicolumn{6}{|l|}{ AST } \\
\hline $\mathrm{BMI}<32.2 \mathrm{~kg} / \mathrm{m}^{2}$ & 0.747 & 0.046 & $0.500-0.995$ & 66.7 & 93.7 \\
\hline$W C<108.5 \mathrm{~cm}$ & 0.806 & 0.014 & $0.587-1.000$ & 66.7 & 93.7 \\
\hline VFA $<121.3 \mathrm{~cm}^{2}$ & 0.745 & 0.049 & $\begin{array}{l}0.521- \\
0.968\end{array}$ & 66.7 & 78.1 \\
\hline \multicolumn{6}{|l|}{ ALT } \\
\hline $\mathrm{BMI}<26.5 \mathrm{~kg} / \mathrm{m}^{2}$ & 0.782 & 0.001 & $\begin{array}{l}0.665- \\
0.899\end{array}$ & 85.7 & 63.2 \\
\hline$W C<95.3 \mathrm{~cm}$ & 0.806 & 0.000 & $\begin{array}{l}0.671- \\
0.941\end{array}$ & 78.6 & 80.7 \\
\hline VFA $<130.2 \mathrm{~cm}^{2}$ & 0.742 & 0.005 & $\begin{array}{l}0.593- \\
0.892\end{array}$ & 57.1 & 87.7 \\
\hline
\end{tabular}


A multivariate analysis was performed to calculate the risk of lipid metabolism disorder and liver dysfunction using the obtained cut-off values (Table 4). The results showed that VFA $>80.2 \mathrm{~cm}^{2}(\mathrm{OR}=$ $2.81, p=0.034), V F A>125.3 \mathrm{~cm}^{2}(O R=18.75, P=0.01)$ and $W C>95.3 \mathrm{~cm}(O R=6.55, p=0.023)$ were significantly related to HDL disorder, LDH disorder and ALT disorder, respectively (Table 5).

Table 5

$\mathrm{BMI}, \mathrm{WC}$ and VFA as variables to predict lipid metabolism disorder and liver disfunction logistic regression analysis

\begin{tabular}{|lllll|}
\hline Category & B & P value & OR & $95 \% \mathrm{Cl}$ \\
\hline HDL disorder & & & & \\
\hline VFA $<80.2 \mathrm{~cm}^{2}$ & 1.03 & 0.034 & 2.81 & $1.08-7.30$ \\
\hline LDH disorder & & & & \\
\hline VFA $<125.3 \mathrm{~cm}^{2}$ & 2.93 & 0.01 & 18.75 & $2.00-176.03$ \\
\hline AST disorder & & & & \\
\hline BMI $<32.2 \mathrm{~kg} / \mathrm{m}^{2}$ & 1.00 & 0.513 & 2.72 & $0.14-54.36$ \\
\hline WC $<108.5 \mathrm{~cm}^{1}$ & 1.00 & 0.513 & 2.72 & $0.14-54.36$ \\
\hline VFA $<121.3 \mathrm{~cm}^{2}$ & 0.10 & 0.890 & 1.11 & $0.26-4.71$ \\
\hline ALT disorder & & & & \\
\hline BMI $<26.5 \mathrm{~kg} / \mathrm{m}^{2}$ & -1.21 & 0.195 & 0.30 & $0.05-1.86$ \\
\hline WC $<95.3 \mathrm{~cm}$ & 1.88 & 0.023 & 6.55 & $1.29-33.25$ \\
\hline VFA $<130.2 \mathrm{~cm}^{2}$ & 1.35 & 0.097 & 3.86 & $0.78-19.06$ \\
\hline
\end{tabular}

\section{Discussion}

In the present study, our results indicate VFA was better related to the lipid metabolism;especially serum $H D L$, LDL levels and liver function variables such as LDH, AST and ALT. In the diagnosis of obesity, the measurements of VFA as a simple, noninvasive and harmless method by BIA was credible. It reveals that VFA was strongly related to the HDL and LDL metabolism than BMI and WC, this may indicate VFA was an independent risk factor for lipid metabolism disorder in the diagnosis of obesity. HDL is a normal biomarker in the metabolism of serum lipid and related to cardiovascular diseases ${ }^{[23]}$. In the research of abdominal adipose tissue and serum HDL-cholesterol, Despres suggested body fat topography and serum HDL was positively associated ${ }^{[24]}$. Bora has been found people with central obesity had significantly greater odds of developing decreased serum HDL level[ ${ }^{[25]}$, and similar results was showed in Canterin's study (Obese subjects have lower aerum HDL cholesterol level) ${ }^{[26]}$. Rodriguez et al conducted 
one study on the association of hepcidin with triglyceride-rich lipoprotein dyslipoproteinemia, small dense LDL and insulin resistance in adolescents, and results showed major changes in adolescents with obesity ${ }^{[27]}$. All these studies suggested VFA was strongly related to lipid metabolism, especially with HDL and similar results were obtained in our study. More than previous studies, our research has been suggested the ROC curve and optimum cut-off point for VFA in the risk prompting of lipid metabolism disorder $\left(80.2 \mathrm{~cm}^{2}, \mathrm{OR}=2.81\right)$.

LDH represents a suitable criterion for the identification of type of energy production, and any changes in isoenzyme pattern probably indicate an alteration of the tissue metabolism ${ }^{[28]}$. LDH was present in adipose tissues of rat, and their distribution was significantly altered by metabolic stress ${ }^{[29]}$. For this study, compared with normal group, VFA was larger in LDH disorder group; the premium cut-off and sensitivity plus specificity was $125.3 \mathrm{~cm}^{2}$ and $162.2 \%$, respectively. By multiple logistic regression analysis, VFA was an independent risk factor for $\mathrm{LDH}$ disorder $(\mathrm{OR}=18.75)$. This may indicate that VFA deposit is the risk factor for LDH disorder and fatty liver. Besides LDH, there is a consensus that liver function enzymes, such as AST and ALT, are biomarkers that reflect liver function ${ }^{[30]}$. Serum AST and ALT concentrations increased with body weight gain, ALT $<2$ times upper limits of normal had a negative predictive value of $95 \%$ for ruling out significant inflammatory activity among patients without liver fibrosis $^{[31]}$. Metabolic disturbances as insulin resistance, dyslipidemia and hyperglycemia are closely related to elevated serum ALT level; a cut-off point of AST/ALT ratio $<1$ has been defined for hepatic steatosis assessment in obese patients ${ }^{[32]}$. In Pirimoglu's study, a strong correlation between liver fat fraction values and AST and ALT levels in children who are overweight and obese were found ${ }^{[33]}$. In our study, the AST and ALT disorder groups showed a higher VFA and the premium cut-off points of VFA were $108.5 \mathrm{~cm}^{2}$ and $130.2 \mathrm{~cm}^{2}$, respectively.

\section{Conclusion}

VFA was more reliable and related to the lipid metabolism and liver function. VFA could be used as an independent indicator for the evaluation of the risk lipid metabolism disorder and liver dysfunction in the normal physical examination and obesity diagnosis.

\section{Declarations}

\section{Ethical and Consent:}

Ethical Review: Except outpatient necessary diagnosis testing, this study does not involve any additional human testing. Ethical approval was waived.

Informed Consent: Written informed consent was obtained from all study participants.

\section{Consent for publication:}


All presentations of case reports have consent for publication.

\section{Availability of data and materials:}

The datasets during and/or analysed during the current study available from the corresponding author on reasonable request.

\section{Competing interest:}

the authors declared that we do not have any commercial or associative interest that represents a conflict of interest in connection with the work submitted.

\section{Funding:}

This study was financially Supported by National Natural Science Foundation of China (No. 82073551 and 81872618)

\section{Authors' contributions:}

The authors thank the Laian People's Hospital for supporting this work of data collection. We also thank for professor Sun Guiju, who has provided me with valuable guidance in the writing of this manuscript. Pan Youwen, Wang Bin, Wang Wei, Xia Hui for their constructive data collection and analysis. All authors read and approved the final manuscript.

\section{Acknowledgement:}

Not applicable.

\section{References}

1. World Health Organization. Obesity and Overweight.Available online: https://www.who.int/newsroom/fact-sheets/detail/obesity-and-overweight (accessed on 9 june 2021). [J]..

2. World Health Organization. Global action plan for the prevention and control of noncommunicable diseases 2013-2020. World Health Organization. https://apps.who.int/iris/handle/10665/94384 [J].

3. CHUA K Y, LIN X, WANG Y, et al. Visceral fat area is the measure of obesity best associated with mobility disability in community dwelling oldest-old Chinese adults [J]. BMC Geriatr. 2021;21(1):282.

4. BERTIN B, DESREUMAUX P. DUBUQUOY L. Obesity, visceral fat and Crohn's disease [J]. Curr Opin Clin Nutr Metab Care. 2010;13(5):574-80.

5. JUNG S H, HA K H KIMDJ. Visceral Fat Mass Has Stronger Associations with Diabetes and Prediabetes than Other Anthropometric Obesity Indicators among Korean Adults [J]. Yonsei Med J. 2016;57(3):674-80.

6. HABERKA M, STOLARZ-SKRZYPEK K, BIEDRON M, et al. Obesity, Visceral Fat, and HypertensionRelated Complications [J]. Metab Syndr Relat Disord. 2018;16(10):521-9. 
7. WANG M, TAN Y, SHI Y, et al. Diabetes and Sarcopenic Obesity: Pathogenesis, Diagnosis, and Treatments [J]. Frontiers in endocrinology, 2020, 11(568.

8. DITTMAR M, REBER H, KAHALY GJ. Bioimpedance phase angle indicates catabolism in Type 2 diabetes [J]. Diabet Med. 2015;32(9):1177-85.

9. SHIN JH, KIM C R, PARK K H, et al. Predicting clinical outcomes using phase angle as assessed by bioelectrical impedance analysis in maintenance hemodialysis patients [J]. Nutrition. 2017;41:7-13.

10. PLAYER E L, MORRIS P, THOMAS T, et al. Bioelectrical impedance analysis (BIA)-derived phase angle $(P A)$ is a practical aid to nutritional assessment in hospital in-patients [J]. Clin Nutr. 2019;38(4):1700-6.

11. WONG JC, O'NEILL S, BECK B R, et al. Comparison of obesity and metabolic syndrome prevalence using fat mass index, body mass index and percentage body fat [J]. PLoS One. 2021;16(1):e0245436.

12. HEO J E, SHIM JS, LEE H, et al. Association between the Thigh Muscle and Insulin Resistance According to Body Mass Index in Middle-Aged Korean Adults [J]. Diabetes metabolism journal. 2020;44(3):446-57.

13. FLOWERS E, LIN F, KANDULA N R, et al. Body Composition and Diabetes Risk in South Asians: Findings From the MASALA and MESA Studies [J]. Diabetes Care. 2019;42(5):946-53.

14. BOUCHI R, SONODA N, ITOH J, et al. Effects of intensive exercise combined with dapagliflozin on body composition in patients with type 2 diabetes: a randomized controlled trial [J]. Endocrine journal. 2021;68(3):329-43.

15. KIM K, PARK SM. Association of muscle mass and fat mass with insulin resistance and the prevalence of metabolic syndrome in Korean adults: a cross-sectional study [J]. Sci Rep. 2018;8(1):2703.

16. BADAWI A, LIU CJ. Obesity and Prevalence of Latent Tuberculosis: A Population-Based Survey [J]. Infectious diseases. 2021;14:1178633721994607.

17. VON DURING M E, JENSSEN T, BOLLERSLEV J, et al. Visceral fat is better related to impaired glucose metabolism than body mass index after kidney transplantation [J]. Transplant international: official journal of the European Society for Organ Transplantation. 2015;28(10):1162-71.

18. STURM W, SANDHOFER A, ENGL J, et al. Influence of visceral obesity and liver fat on vascular structure and function in obese subjects [J]. Obesity. 2009;17(9):1783-8.

19. SOLDEVILA L, TENESA M, HORNEROS J, et al. Association Between Visceral Abdominal Fat Accumulation and Severity of Liver Fibrosis in Nondiabetic Individuals Coinfected by Human Immunodeficiency Virus and Hepatitis C Virus [J]. AIDS Res Hum Retroviruses. 2020;36(3):205-13.

20. DARVISHI-KHEZRI H, KARAMI H, NADERISORKI M, et al. Moderate to severe liver siderosis and raised AST are independent risk factors for vitamin D insufficiency in beta-thalassemia patients [J]. Sci Rep. 2020;10(1):21164.

21. ABRAHAM M A, RASTI M. BAUER P V, et al. Leptin enhances hypothalamic lactate dehydrogenase $A$ (LDHA)-dependent glucose sensing to lower glucose production in high-fat-fed rats [J]. J Biol Chem. 
2018;293(11):4159-66.

22. NANTSUPAWAT N, BOONCHAROEN A, WISETBORISUT A, et al. Appropriate Total cholesterol cut-offs for detection of abnormal LDL cholesterol and non-HDL cholesterol among low cardiovascular risk population [J]. Lipids Health Dis. 2019;18(1):28.

23. WOUDBERG N J, PEDRETTI S, LECOUR S, et al. Pharmacological Intervention to Modulate HDL: What Do We Target? [J]. Frontiers in pharmacology, 2017, 8(989.

24. DESPRES JP, TREMBLAY A, PERUSSE L, et al. Abdominal adipose tissue and serum HDL-cholesterol: association independent from obesity and serum triglyceride concentration [J]. Int $\mathrm{J}$ Obes. 1988;12(1):1-13.

25. BORA K, PATHAK M S, BORAH P, et al. Association of Decreased High-Density Lipoprotein Cholesterol (HDL-C) With Obesity and Risk Estimates for Decreased HDL-C Attributable to Obesity: Preliminary Findings From a Hospital-Based Study in a City From Northeast India [J]. Journal of primary care community health. 2017;8(1):26-30.

26. CANTERIN A A, CIGNACCO G B DONADONV, et al. [Pordenone study: HDL-cholesterol and obesity indexes in the young] [J]. Giornale italiano di cardiologia. 1992;22(8):899-903.

27. RODRIGUEZ-MORTERA R, CACCAVELLO R, HERMO R, et al. Higher Hepcidin Levels in Adolescents with Obesity Are Associated with Metabolic Syndrome Dyslipidemia and Visceral Fat [J]. Antioxidants, 2021, 10(5).

28. PROCHAZKA B, QURESHI M A, MATTY A J. Lactate dehydrogenase activity and isoenzyme patterns in skeletal muscle, fat, exocrine pancreas and isolated pancreatic islets of normal and obeseHyperglycaemic mice [J]. Diabetologia. 1970;6(5):493-8.

29. PANDURANGAN M, KIM DH. ZnO nanoparticles augment ALT, AST, ALP and LDH expressions in C2C12 cells [J]. Saudi journal of biological sciences. 2015;22(6):679-84.

30. LIU Y, ZHAO P, CHENG M, et al. AST to ALT ratio and arterial stiffness in non-fatty liver Japanese population:a secondary analysis based on a cross-sectional study [J]. Lipids Health Dis. 2018;17(1):275.

31. BROUWER W P SONNEVELDMJ, HANSEN B E, et al. Very low probability of significant liver inflammation in chronic hepatitis B patients with low ALT levels in the absence of liver fibrosis [J]. Alimentary pharmacology \& therapeutics, 2020, 52(8): pp. 1399-406.

32. BOTROS M, SIKARIS K A. The de ritis ratio: the test of time [J]. The Clinical biochemist Reviews. 2013;34(3):117-30.

33. PIRIMOGLU B, SADE R, POLAT G, et al. Analysis of correlation between liver fat fraction and AST and ALT levels in overweight and obese children by using new magnetic resonance imaging technique [J]. The Turkish journal of gastroenterology: the official journal of Turkish Society of Gastroenterology. 2020;31(2):156-62.

\section{Figures}



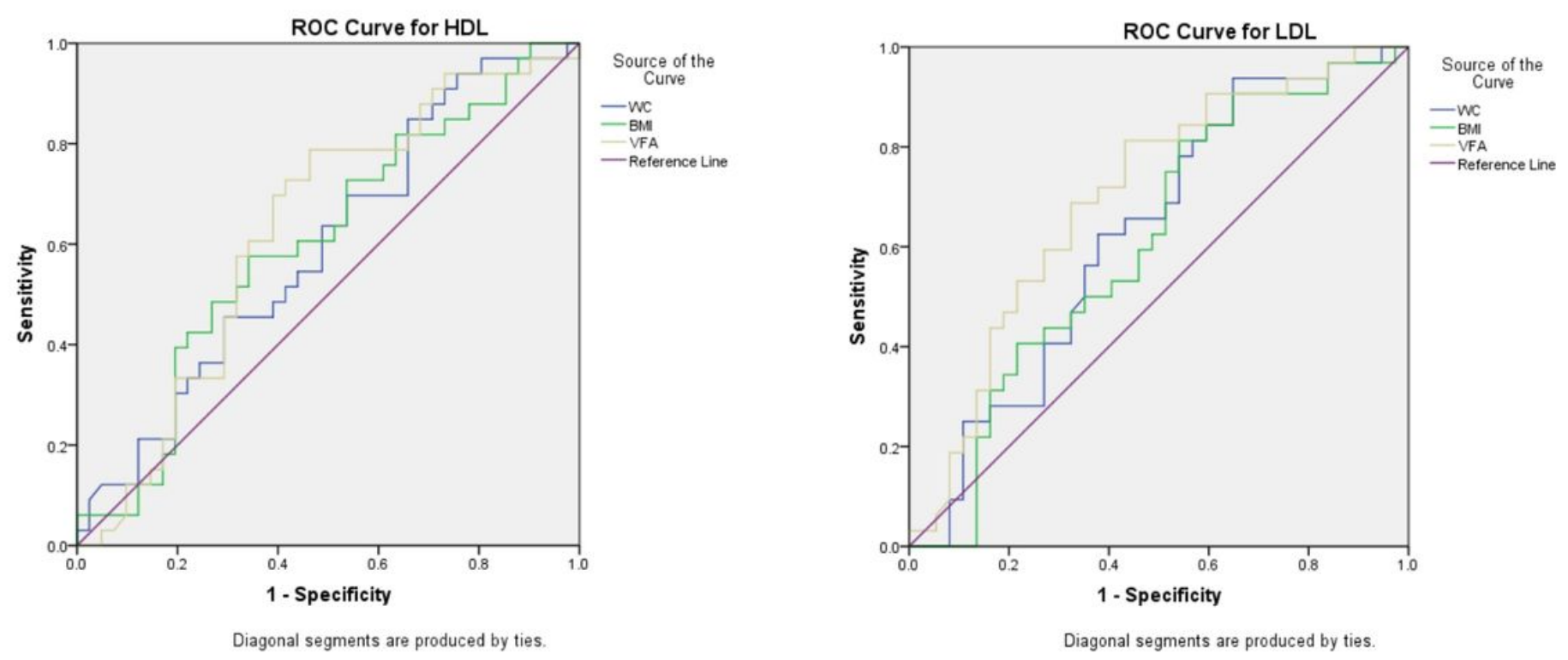

Figure 1

ROC curve of BMI, WC and VFA predicational ability for HDL and LDL indicators
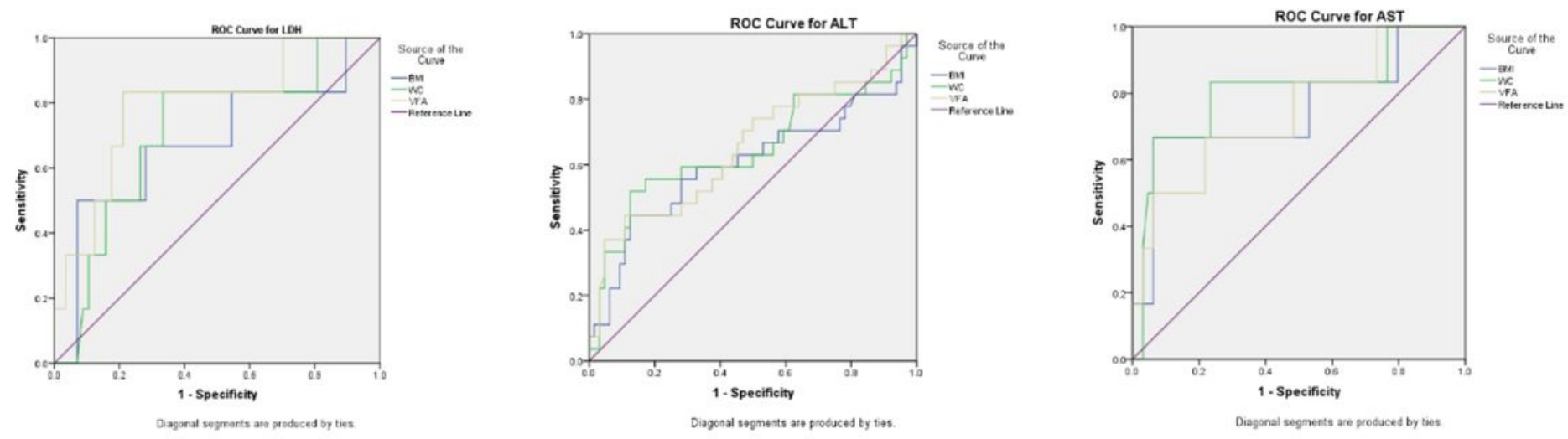

Figure 2

ROC curve of BMI, WC and VFA predicational ability for LDH, ALT and AST indicators 